\title{
Amnesia of inhibitory avoidance by scopolamine is overcome by previous open-field exposure
}

\author{
Natalia C. Colettis, ${ }^{1}$ Marina Snitcofsky, ${ }^{1}$ Edgar E. Kornisiuk, ${ }^{1}$ Emilio N. Gonzalez, ${ }^{1}$ \\ Jorge A. Quillfeldt, ${ }^{2}$ and Diana A. Jerusalinsky ${ }^{1}$ \\ ${ }^{1}$ Laboratorio de Neuroplasticidad y Neurotoxinas (LaNyN), Instituto de Biología Celular y Neurociencias (IBCN), UBA-CONICET, \\ Facultad de Medicina, Universidad de Buenos Aires, Buenos Aires 1121, Argentina; ${ }^{2}$ Laboratório de Psicobiologia e Neurocomputação, \\ Depto. de Biofísica, UFRGS, Porto Alegre 91501-970, Brazil
}

\begin{abstract}
The muscarinic cholinergic receptor (MAChR) blockade with scopolamine either extended or restricted to the hippocampus, before or after training in inhibitory avoidance (IA) caused anterograde or retrograde amnesia, respectively, in the rat, because there was no long-term memory (LTM) expression. Adult Wistar rats previously exposed to one or two open-field (OF) sessions of 3 min each (habituated), behaved as control animals after a weak though over-threshold training in IA. However, after OF exposure, IA LTM was formed and expressed in spite of an extensive or restricted to the hippocampus MAChR blockade. It was reported that during and after OF exposure and reexposure there was an increase in both hippocampal and cortical ACh release that would contribute to "prime the substrate," e.g., by lowering the synaptic threshold for plasticity, leading to LTM consolidation. In the frame of the "synaptic tagging and capture" hypothesis, plasticity-related proteins synthesized during/after the previous OF could facilitate synaptic plasticity for IA in the same structure. However, IA anterograde amnesia by hippocampal protein synthesis inhibition with anisomycin was also prevented by two OF exposures, strongly suggesting that there would be alternative interpretations for the role of protein synthesis in memory formation and that another structure could also be involved in this "OF effect."
\end{abstract}

[Supplemental material is available for this article.]

It has long been recognized that the cholinergic system plays an important role in learning and memory (Deutsch and Rocklin 1967; Huang et al. 2010; see Jerusalinsky et al. 1997) and that the forebrain cholinergic transmission could be relevant for arousal and attention (see Sarter and Bruno 2000; Sarter et al. 2003). Antagonism of muscarinic acetylcholine receptors produces cognitive deficits in both experimental animals and humans (Baratti et al. 1979; Morris et al. 1982; Auerbach and Segal 1994; Miranda and Bermudez-Rattoni 1999; Diehl et al. 2007; for reviews, see Nadel and Moscovitch 1997; Eichenbaum et al. 1999; Frankland and Bontempi 2005; Eglen 2006).

Habituation is the most elemental type of non-associative learning and is based on the decrease of the response to the stimulus. Habituation of an animal to a new environment is revealed by a decrease in its exploratory behavior. There is an activation of the hippocampus and its medial septum cholinergic afference while a rodent explores an open field (OF) and habituates to it (Izquierdo et al. 1992; Thiel et al. 1998). This involves several processes, such as responses to novelty (including arousal), emotion, moderate stress, decreased response due to recognition of (familiarization with) the environment, which requires spatial learning and memory leading to recognition and retrieval. Hippocampal lesions or blockade of the hippocampal cholinergic muscarinic receptors (MAChR) dramatically affected exploratory behavior and habituation to the environment, in both rats and mice (Ukai et al. 1994; see Izquierdo and Medina 1997). In addition, cortical and hippocampal acetylcholine (ACh) release impacts attention (see Everitt and Robbins 1997; Sarter et al. 2003), learning and memory of various tasks (see Jerusalinsky et al. 1997; Pepeu and

Corresponding author: djerusal@gmail.com

Article is online at http://www.learnmem.org/cgi/doi/10.1101/lm.036210.114.
Giovannini 2004) and is critical for hippocampal synaptic plasticity like long-term potentiation (LTP) (Auerbach and Segal 1994; Sanchez et al. 2009).

The inhibitory avoidance (IA) task is a paradigm of associative learning that can be acquired in a single training session through the activation of several brain structures, such as the amygdala, hippocampus, and various cortical regions, which are recruited by several sensory stimuli, including spatial and visual components, (mild) pain, and fear (see Izquierdo 1989).

Acquisition of an IA task also depends on the activation of the cholinergic system. In the rat, the systemic (Giovannini et al. 1999) or intracerebral (intrahippocampal, intra-amygdala, intra-antero-lateral prefrontal, and posterior parietal cortex; see Izquierdo et al. 1999b) administration of a muscarinic antagonist before or after IA training impaired performance, leading to amnesia (Bammer 1982; Izquierdo et al. 1992; for reviews, see Jerusalinsky et al. 1997; McGaugh and Izquierdo 2000; Klinkenberg and Blokland 2010). On the other hand, agonist administration resulted in a better IA performance for rats and mice, evaluated $24 \mathrm{~h}$ after training; hence, it improves long-term memory (LTM) (Baratti et al. 1979; Barros et al. 2002).

It was shown that exposure to either a novel task or a novel environment certain time before IA training led to several different interactions between tasks (see Supplemental Table); i.e., 2-min OF exposure $1 \mathrm{~h}$ after IA training (with 0.4 - or 1-mA footstock) or two ( 2 min each) OF exposures 5 min before and $1 \mathrm{~h}$ after

\footnotetext{
(C) 2014 Colettis et al. This article is distributed exclusively by Cold Spring Harbor Laboratory Press for the first 12 months after the full-issue publication date (see http://learnmem.cshlp.org/site/misc/terms.xhtml). After 12 months, it is available under a Creative Commons License (Attribution-NonCommercial 4.0 International), as described at http://creativecommons.org/licenses/by-nc/ $4.0 /$
} 
IA training interfered on IA performance in the test session carried out $24 \mathrm{~h}$ later (Izquierdo et al. 1999a). On the other hand, a 2-min exposure to a different box $2 \mathrm{~h}$ before IA training had no evident effect on this task (Netto et al. 1985). OF interference was evident when rats were exposed $2 \mathrm{~h}$ after IA training, but not when they were exposed $6 \mathrm{~h}$ after IA training (Izquierdo et al. 1999a). It was also reported that a 5-min OF exposure around a weak IA training session ( $1 \mathrm{~h}$ before and either $15 \mathrm{~min}$ or $1 \mathrm{~h}$ after training) with an underthreshold stimulus, which would not lead to LTM formation, could promote the establishment of an IA-LTM (Moncada and Viola 2007).

In our behavioral assays, we currently let the animals explore twice an OF in two consecutive days before training them in different behavioral tasks. Rats that were then trained in IA and received current amnestic antagonists showed variable performances that appeared to depend on whether they were or were not previously exposed to the OF. Taking into account our experience and the mentioned reports, we have evaluated the putative influence of the exploration and habituation to an OF, an experience with nonaversive content, on the amnesia of an aversive task, like IA to a footshock, caused by the muscarinic receptor antagonist scopolamine. Aiming to this goal, we assessed the influence of the previous OF on IA performance in groups of adult Wistar rats either treated with or without scopolamine. In this work, we show that the previous experience in the OF allowed to overcome the amnesia in IA caused by scopolamine administered either intraperitoneally or intrahippocampus, therefore leading to LTM formation and expression.

\section{Results}

\section{Footshock intensity for the inhibitory avoidance task}

Adult male Wistar rats were trained under current experimental conditions in our laboratory in a step-down IA task. To evaluate the threshold footshock which leads to LTM expression, 35 rats were divided into three groups and trained with $0.4,0.5$, or 0.6-mA footshock, respectively (Fig. 1A). There were no significant differences between training latencies for the three groups, indicating that those groups were comparable because most of the
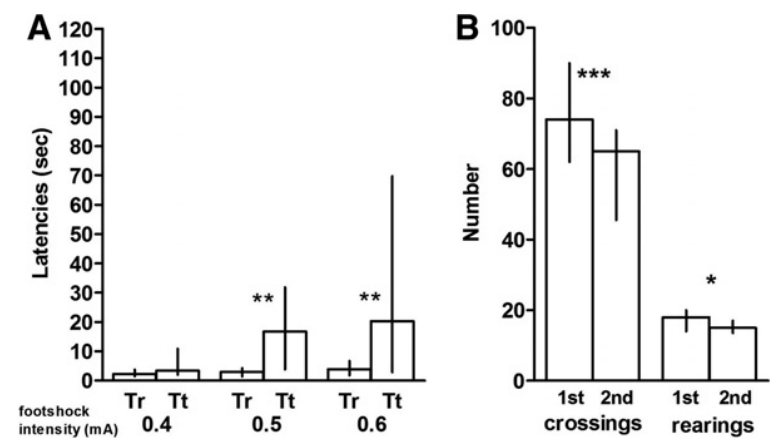

Figure 1. Effect of footshock intensity effect on IA learning and memory. (A) Bars represent medians of latencies with interquartile ranges (percentiles $25 ; 75$ ) of rats trained with different footshock intensities. (Tr) Training session; (Tt) test session. $\left(^{* *}\right)$ Significant differences between training and test latencies within the same group (Wilcoxon paired $t$-test, $[* *] P<0.01) ; 0.4-, 0.5$-, and $0.6-\mathrm{mA}$ trained groups; $n=12,12$, and 11, respectively. (B) Example of the OF performance. Rats were exposed to two 3-min OF sessions, $24 \mathrm{~h}$ apart. Bars represent median with interquartile ranges (percentiles $25 ; 75$ ) of the number of crossings and rearings. Those rats exposed to the OF with this protocol showed significant habituation. $\left({ }^{*},{ }^{* *}\right)$ Significant differences between the first and the second OF sessions (Wilcoxon paired $t$-test, $\left[{ }^{*}\right] P<$ 0.05 or $[* * *] P<0.001)$. rats showed a similar behavior during the training session. The test session was performed $24 \mathrm{~h}$ later without a footshock, as indicated in Materials and Methods.

We consider that the learning criterion is reached when test latencies are higher than training latencies. The medians of latencies are represented in Figure 1A. Most of the rats that were trained with 0.5- and 0.6-mA footshocks reached the learning criterion; therefore, they expressed an LTM. On the other hand, rats that were trained with $0.4 \mathrm{~mA}$ did not reach the learning criterion. Hence, this indicates that the threshold footshock was $\sim 0.5 \mathrm{~mA}$.

\section{Habituation to the OF}

To assess habituation to the OF, the number of crossings and rearings was recorded for each rat (Fig. 1B). Every group of animals exposed to two OF (3-min) sessions $24 \mathrm{~h}$ apart had a significant decrease in the median of total number of rearings and/or crossings in the second OF session compared with the first one, showing that the OF protocol used in this work led to habituation to the arena (Fig. 1B).

\section{OF effect on memory of the inhibitory avoidance \\ OF effect on STM of IA}

To evaluate a putative effect of the OF on IA STM, two groups of animals, either not exposed to the OF (no OF) or exposed in two consecutive days to the OF (two OF), were then trained in IA with a $0.5-\mathrm{mA}$ footshock $90 \mathrm{~min}$ after the second OF session and were tested $40 \mathrm{~min}$ later without footshock. The medians of IA latencies following $\mathrm{OF}$ exposure are shown in Figure 2A. There were neither significant differences between IA training latencies nor between test latencies when comparing the group of animals twice exposed to the OF with that not exposed to the OF (Fig. 2A). Both groups of rats showed significantly higher test than training latencies when IA sessions were $40 \mathrm{~min}$ apart, revealing that an STM was formed and expressed. Furthermore, there was no significant difference in performance between the groups. Hence, these results indicate that there was no evident effect of the previous OF on IA STM.

\section{OF effect on LTM of IA}

To evaluate whether there was any effect of the OF on IA LTM, rats were exposed $3 \mathrm{~min}$ to the $\mathrm{OF}$ and reexposed $24 \mathrm{~h}$ later, as before. Ninety minutes after the second OF, they were trained in IA with a 0.5 -mA footshock; the test was performed $24 \mathrm{~h}$ later without footshock.

There was neither significant difference between training latencies nor between test latencies when comparing the group twice exposed to the OF against the group not exposed (Fig. 2B). Both groups of rats showed significantly higher test than training latencies. Hence, the learning criterion was reached, indicating that an LTM was formed and expressed, as it was for STM. No significant differences were found in IA performance between the groups of animals either exposed or not to two OF sessions (Fig. 2B).

\section{OF effect on amnesia of IA instigated by systemic scopolamine}

To assess a putative influence of the previous OF exposure on the amnesia instigated by the muscarinic antagonist scopolamine during memory acquisition and/or early consolidation of IA, we repeat same protocol as in Habituation to the OF. The rats in each of the two groups were injected i.p. either with saline 


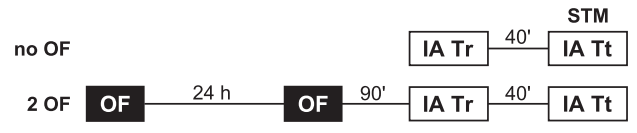

A
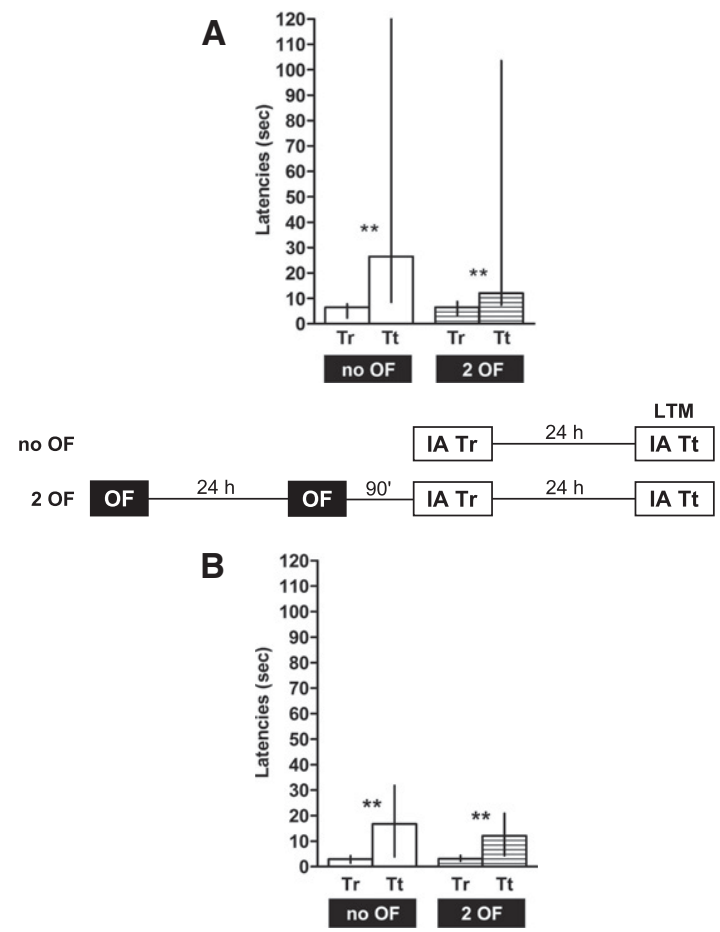

Figure 2. Effect of open-field (OF) exposure on IA STM and LTM. (Top panels) Diagram of the experimental design. $(A, B)$ Bars represent IA-STM $(A)$ or LTM $(B)$ performance of naïve rats either not exposed to the OF (no OF groups, empty bars), or exposed to two OF sessions (two OF groups, horizontal striped bars). Bars represent medians of latencies with interquartile ranges (percentiles 25; 75). (Tr) Training session; (Tt) test session. $\left({ }^{* *}\right)$ Significant differences between training and test latencies (Wilcoxon paired $t$-test, $\left({ }^{* *}\right) P<0.01$ ). No OF groups, $n=12$; two OF groups, $n=11$.

(control groups) or scopolamine $(1 \mathrm{mg} / \mathrm{kg}) 20 \mathrm{~min}$ before training in IA with 0.5-mA footshock (Figs. 3, 4).

\section{OF effect on IA STM impairment by systemic scopolamine}

To assess IA-STM rats were tested $40 \mathrm{~min}$ after IA training. The median of IA latencies are shown in Figure 3A. Training latencies of rats either submitted or not to the OF, injected with saline or scopolamine were not statistically different (Fig. 3A).

Scopolamine treated rats, either exposed or not to the OF, did not express STM. Control groups injected with saline, either exposed or not to two OF sessions clearly expressed an STM (Fig. 3A), since test latencies were significantly higher than training latencies. The STM performance was higher in control groups compared with scopolamine injected rats, either exposed or not exposed to the OF (Fig. 3B). Therefore, i.p. scopolamine produced the already reported "STM amnesia" of IA, and the previous OF exposure did not show any significant effect on it.

However, shorter test latencies following the systemic administration of scopolamine could be due to an enhancement of locomotor activity (Day et al. 1991; Pitsikas et al. 2001), instead of a negative effect on cognitive function. Therefore, the locomotor activity was assessed $60 \mathrm{~min}$ after i.p. administration (same interval between i.p. injection and the IA-STM test) of same dose of scopolamine $(1 \mathrm{mg} / \mathrm{kg})$. There were no significant differences in the number of crossings and rearings between scopolamine and saline injected animals, and the observed behavior was rather similar (see Table 1).

\section{OF effect on IA LTM amnesia by systemic scopolamine}

The results of IA latencies for test and training sessions performed $24 \mathrm{~h}$ apart are shown in Figure 4,A and B. There was no difference in training latencies between groups. There were significant differences between training and test latencies in saline injected rats either exposed or not to the OF, while no significant difference was observed between test and training latencies for the group of rats without OF exposure, injected with scopolamine (Fig. 4A,B); furthermore, latency differences (test - training latencies) for scopolamine injected group were significantly lower than for both saline injected groups (Fig. 4C). Hence, rats injected with scopolamine and not exposed to OF did not express an LTM. On the other hand, test latencies were significantly higher than training latencies for the rats twice exposed to the OF and then injected with scopolamine (Fig. 4A).

Then we asked whether only one OF exposure ( $90 \mathrm{~min}$ before IA training) would also have any effect on scopolamine amnesia. However, we first need to find out if one OF exposure could have any effect on IA performance in the conditions of our assays. To this end, (test - training) latency differences from control rats exposed to one OF $90 \mathrm{~min}$ before IA training were compared with latency differences from control rats not exposed to the OF. There was no significant difference between latency differences; both groups reached the learning criterion (Fig. 4B), as did naïve animals (legend of Fig. 4B).

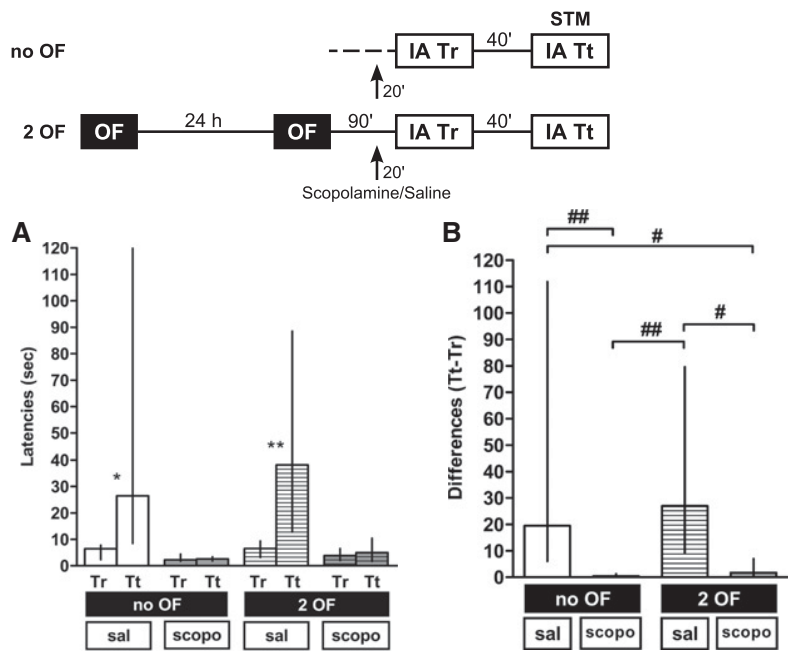

Figure 3. OF effect on IA-STM impairment produced by systemic infusion of scopolamine. (Top panel) Diagram of the experimental design. Saline or scopolamine infusion, indicated by arrows, was given 20 min before IA training. $(A, B)$ IA performance of rats not exposed to the OF (no OF, empty bars), or previously exposed to two OF sessions (two OF, striped bars). Rats were injected intraperitoneally 20 min before IA training (with 0.5-mA footshock) with either saline (sal, white bars) or scopolamine $1 \mathrm{mg} / \mathrm{kg}$ (scopo, gray bars); they were tested 40 min later to evaluate IA-STM. (A) Bars represent medians of latencies with interquartile ranges (percentiles $25 ; 75)$. (Tr) Training session; (Tt) test session. $(*, * *)$ Significant differences between training and test latencies within the same group (Wilcoxon paired $t$-test, $\left[{ }^{*}\right] P<0.05,\left[{ }^{* *}\right] P<0.01$ ). (B) Latency differences (STM Tt - Tr) for the same groups in $A$. Bars represent medians of latency differences with interquartile ranges (percentiles $25 ; 75)$. (\#, \#\#) Significant differences among latency differences (Multiple Comparisons Dunn's Test after ANOVA KruskalWallis, $\left.\left.\left[{ }^{\#}\right] P<0.05,{ }^{\# \#}\right] P<0.01\right)$. No OF groups: control, $n=11$ and scopo, $n=8$. Two OF groups: control, $n=11$ and scopo, $n=9$. 


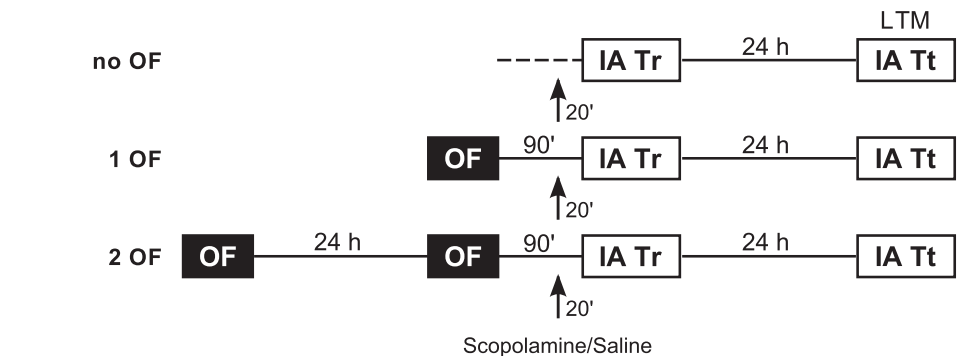

A

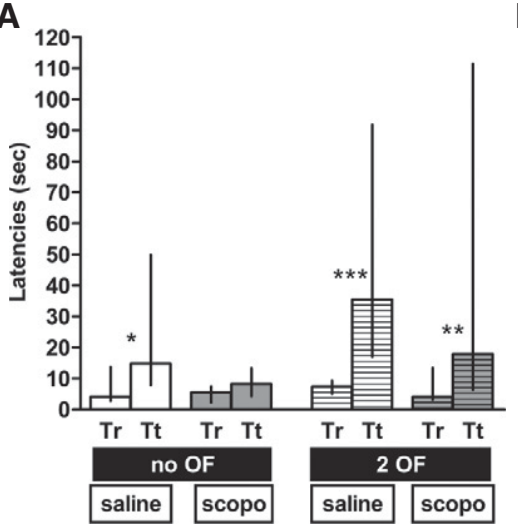

B
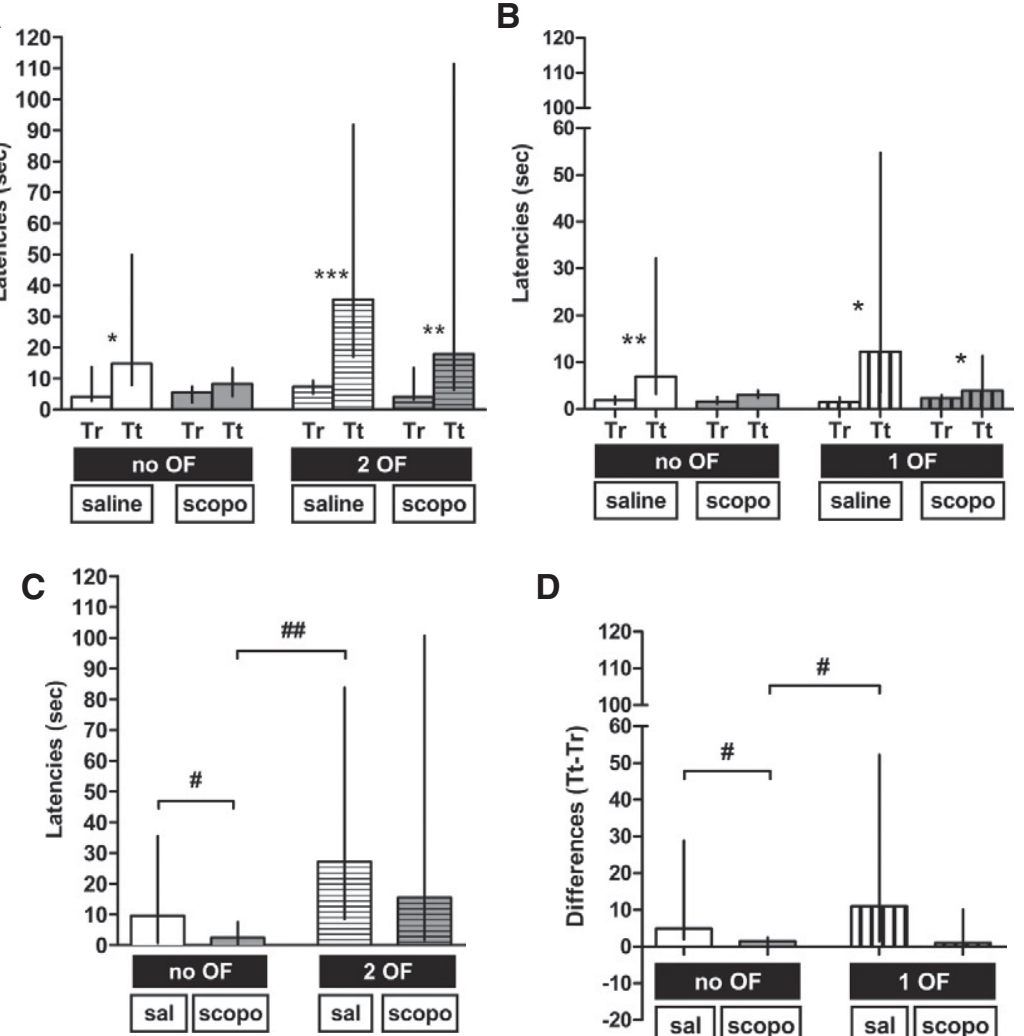

D

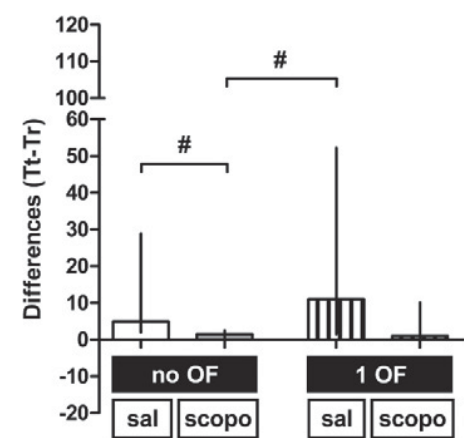

Figure 4. OF effect on IA-LTM amnesia produced by systemic infusion of scopolamine. (Top panel) Diagram of the experimental design. Saline or scopolamine infusion, indicated by arrows, was given 20 min before IA training. IA performance of rats not exposed to the OF (no OF, empty bars) or previously exposed to one or two OF sessions (two OF, horizontal striped bars, in $A$, and one OF, vertical striped bars, in B). Rats were injected intraperitoneally 20 min before IA training (with 0.5 - mA footshock) with either saline (sal, white bars) or scopolamine $1 \mathrm{mg} / \mathrm{kg}$ (scopo, gray bars); they were tested $24 \mathrm{~h}$ later to evaluate IA LTM. $(A, B)$ Bars represent medians of latencies with interquartile ranges (percentiles $25 ; 75)$. (Tr) Training session; (Tt) test session. $\left({ }^{*},{ }^{* *}, * * *\right)$ Significant differences between training and test latencies within the same group (Wilcoxon paired $t$-test, $\left[{ }^{*}\right] P<0.05$, $\left[{ }^{* *}\right]$ $P<0.01$ or $\left.\left[{ }^{* * *}\right] P<0.001\right)$. IA latencies of naïve animals: no OF: Tr: $2.92(1.428 ; 4.24)$, Tt: 16.70 (3.85; 31.84); $n=12, P<0.01$, Wilcoxon paired $t$-test; one OF: Tr: $2.26(1.59 ; 4.47)$, Tt: 11.46 (7.57; 95.88); $n=11, P<0.01$, Wilcoxon paired $t$-test. $(C, D)$ Latency differences (LTM Tt $-\mathrm{Tr}$ ) for the same groups in $A$ and $B$, respectively. Bars represent medians of latency differences with interquartile ranges (percentiles 25; 75). (\#, \#\#)Significant differences among latency differences (Multiple Comparisons Dunn's Test after ANOVA Kruskal-Wallis, $\left.\left.{ }^{\#}\right] P<0.05,\left[{ }^{\#}\right] P<0.01\right) .(A, C)$ No OF groups: control, $n=10$ and scopo, $n=11$. One OF group: control, $n=7$ and scopo, $n=10$. $(B, D)$ No OF groups: control, $n=13$ and scopo, $n=15$. Two OF groups: control, $n=14$ and scopo, $n=12$.

Test latencies of rats exposed to one OF session injected with scopolamine, were significantly higher than training latencies (Fig. 4B). Therefore, this group also achieved the criterion for an established LTM.

The comparison of latency differences showed that both control groups injected with saline, either exposed or not to the OF, developed better performances than the "amnesic group" treated with scopolamine and without previous OF exposure (Fig. 4C,D).
Therefore, these results showed that one or two OF sessions "prevented" the scopolamine induced amnesia of IA. The performance in IA of scopolamine injected rats twice exposed to the $\mathrm{OF}$ was not statistically different than for rats exposed only once (Fig. 4A,B).

\section{OF effect on amnesia of IA instigated by intrahippocampal infusion of scopolamine}

Since scopolamine administered into the hippocampus (8 $\mu \mathrm{g} /$ side) immediately after IA training, at early consolidation, leads to amnesia of IA, we investigated if the previous OF could also improve memory in this case. The experimental design is shown in top panels of Figure 5.

\section{OF effect on IA STM impairment by intrahippocampal scopolamine}

IA latencies for STM are shown in Figure 5A. Significantly higher test than training latencies were observed in rats exploring twice the OF injected with scopolamine, as well as in rats either exposed or not to the OF, injected with saline (Fig. 5A). Therefore, those animals clearly expressed STM. At variance, those rats without OF exposure and treated with intrahippocampal scopolamine, did not reach the learning criterion (Fig. 5A). When comparing groups' performance (Fig. 5B), statistically significant differences were found among latency differences (test - training latencies). The group of rats not exposed to the OF, treated with scopolamine showed the lowest performance for IA STM compared with the other groups (Fig. 5B). Hence, intrahippocampal injection of scopolamine immediately after training impaired IA-STM and this negative effect was prevented by the previous OF sessions.

\section{OF effect on IA LTM amnesia instigated by intrahippocampal scopolamine}

IA performance of rats either previously exposed or not to the $\mathrm{OF}$ is shown in Figure 5C. Taking into account the results with systemic scopolamine, we also included here groups of rats exposed to only one OF. Animals previously exposed once or twice to the $\mathrm{OF}$, infused into the hippocampus either with scopolamine or saline, showed significant differences between test and training latencies; therefore, these rats expressed LTM. On the other hand, there were no significant differences between test and training latencies for the group of rats not exposed to the OF and treated with scopolamine; hence, these rats were amnesic. As expected, test latencies were significantly higher than training latencies for control groups (Fig. 5C). Furthermore, latency differences (test - training latencies) were significantly different 
Table 1. OF performance (crossings and rearings Median with interquartile ranges, IQR) $60 \mathrm{~min}$ after administration either of scopolamine $(1 \mathrm{mg} / \mathrm{kg}$ i.p., $n=12)$ or saline $(n=11)$

\begin{tabular}{lcc}
\hline $\begin{array}{l}\text { OF performance } \\
\text { (Median, IQR) }\end{array}$ & Crossings & \multicolumn{1}{c}{ Rearings } \\
\hline Saline & $52.0(47.0 ; 63.0)$ & $15.0(11.0 ; 23.0)$ \\
Scopolamine & $55.5(47.0 ; 83.0)$ & $10.5(9.0 ; 15.0)$ \\
\hline
\end{tabular}

No significant differences were observed in the number of crossings and rearings between scopolamine and saline injected animals $(P>0.05$, MannWhitney test).

for the group not exposed to the OF and treated with scopolamine, which showed the lowest performance for IA LTM, compared with the other groups (Fig. 5D). There were not significant differences between latency differences of rats injected with saline, exposed either to 1 or 2 OF sessions, thus showing similar IA performances (Fig. 5D).

\section{Effect of hippocampal protein synthesis inhibition on IA performance}

It has been previously reported that the OF exploration for $5 \mathrm{~min}$ promoted IA memory when rats were trained with an underthreshold footshock that usually did not induce LTM; and it was proposed that this effect was dependent on an OF concomitant protein synthesis (Moncada and Viola 2007).

We intended to find out if the OF modulation of IA LTM, evidenced when "retention" was challenged by an amnestic agent, would involve protein synthesis triggered during or after the second OF exposure.

First, we assessed the effect of anisomycin injected either 85 min (5 min after the OF) or 120 min before IA training (with a $0.5-\mathrm{mA}$ footshock) (30 min before the OF), on IA performance of rats tested $24 \mathrm{~h}$ after training. The experimental design is shown in Figure 6.

When anisomycin was infused 85 min before IA training, in rats without OF exposure, there were no significant differences between training and test latencies in IA; it means that the rats did not reach the learning criterion, there was no evident retention and LTM was not expressed (Fig. 6A). When anisomycin was infused 120 min before IA training, test latencies (though lower than usual) resulted significantly higher than training latencies (Fig. 6B). Therefore, anisomycin led to amnesia of IA-LTM when it was injected 85 min before IA training, though not 120 min before. However, in the latest case, anisomycin led to some IA-LTM impairment, since latency differences were significantly lower than those of control rats injected with vehicle (see Fig. 6D).

We then intended to assess whether there was some protein synthesis triggered during or after the second OF exposure, which would be required for the IA trace. Hence, we blocked protein synthesis during or after the second OF session by using anisomycin injected into the dorsal hippocampus $30 \mathrm{~min}$ before or $5 \mathrm{~min}$ after the second OF session. Both groups of animals injected with anisomycin, either 85 or 120 min before IA training, that had been previously exposed to the OF, showed significantly higher test than training latencies; it means that there was retention and the animals clearly expressed an LTM (Fig. 6A,B). Latency differences in IA were significantly higher for rats twice exposed to the OF and injected 120 min before IA training with anisomycin, than for those not exposed to the OF also injected with the drug (Fig. 6D). Hence, the OF exploration also rescued IA-LTM impaired by anisomycin, despite the moment of infusion, either before or after the second OF session.

\section{Discussion}

\section{Effect of a previous experience on IA memory}

In the last 30 years, there were several reports on the effect of a novel experience around the time of IA training, on performance of this task; some of those reports appeared controversial. As shown in the Supplemental Table, the novel experience (mostly OF) could lead to interference in learning and memory of the IA task (when animals were exposed only once $20 \mathrm{~min}$ or $2 \mathrm{~h}$ after IA training, or twice, 5 min before and $2 \mathrm{~h}$ after training), (Netto et al. 1985; Izquierdo and Pereira 1989; Izquierdo et al. 1999a; Blake et al. 2011); in other protocols, this novel experience did

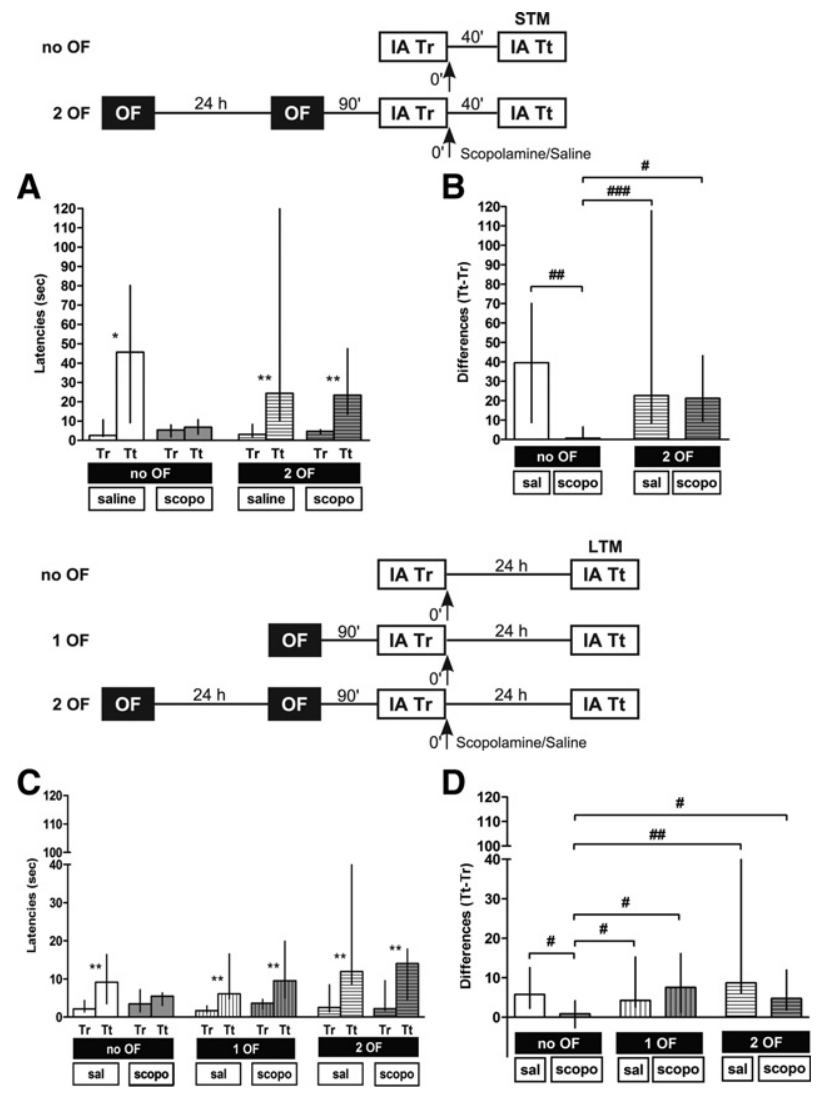

Figure 5. OF effect on IA-STM and LTM impairment produced by intrahippocampal post-training infusion of scopolamine. (Top panels) Diagram of the experimental design. Saline or scopolamine infusion, indicated by arrows, was given immediately after IA training. $(A, C)$ IA performance of rats not exposed to the OF (no OF, empty bars) or previously exposed to OF sessions (one OF, vertical striped bars, and two OF, horizontal striped bars). Rats were injected with either saline (sal, white bars) or scopolamine $8 \mu \mathrm{g} /$ side (scopo, gray bars) and were trained in IA with a $0.5-\mathrm{mA}$ footshock; they were tested 40 min later to evaluate STM $(A)$ or $24 \mathrm{~h}$ later to evaluate LTM (C). Bars represent medians of latencies with interquartile ranges (percentiles $25 ; 75$ ). (Tr) Training session; (Tt) test session. $\left(*,{ }^{*}\right)$ Significant differences between training and test latencies within the same group (Wilcoxon paired $t$-test, $\left[{ }^{*}\right] P<0.05$, $\left[{ }^{* *}\right] \quad P<0.01$ ). (B) Latency differences (STM Tt $-\mathrm{Tr}$ ) for the same groups in $A$. (D) Latency differences (LTM Tt - Tr) for the same groups in $C$. In $B$ and $D$, bars represent medians of latency differences with interquartile ranges (percentiles 25; 75). (\#, \#\#, \#\#\#) Significant differences among latency differences (Multiple Comparisons Dunn's Test after ANOVA Kruskal-Wallis, $\left[{ }^{\#}\right] P<0.05$, $\left[{ }^{\# \#}\right] P<0.01$ or $\left[{ }^{\# \# \#]} P<\right.$ 0.001 ). For $A$ and $B$, no OF groups: control, $n=12$ and scopo, $n=11$. 2 OF groups: control, $n=10$ and scopo, $n=11$. For $C$ and $D$, no OF groups: control, $n=14$ and scopo, $n=10$. One OF group: control, $n=$ 8 and scopo, $n=13$. 2 OF group: control, $n=10$ and scopo, $n=8$. 


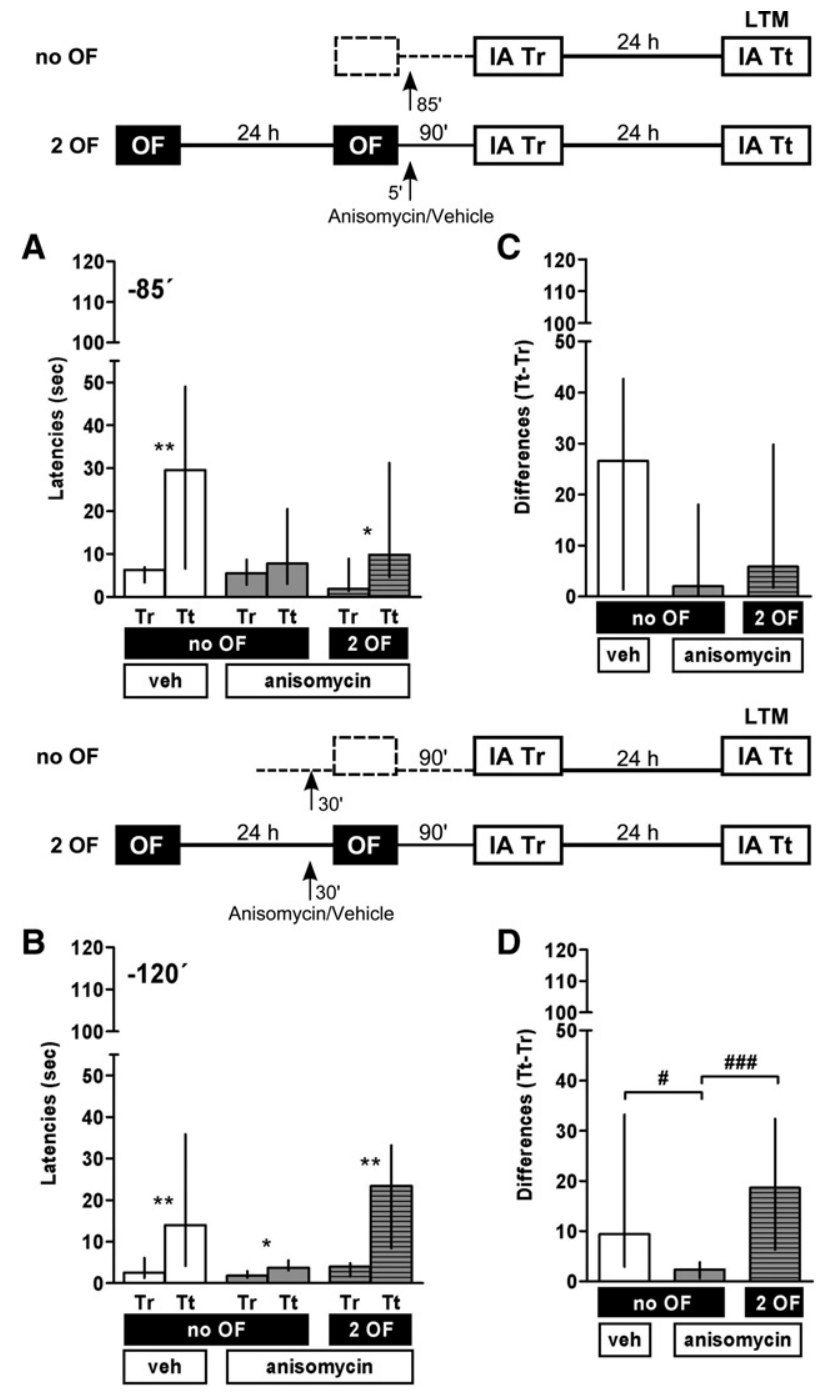

Figure 6. Effect of protein synthesis inhibition on IA performance. OF effect on anisomycin IA-LTM amnesia. (Top panel) Diagram of the experimental design. Vehicle or anisomycin intrahippocampal infusion is indicated by arrows. IA performance of rats not exposed to the OF (no OF, empty bars) or previously exposed to two OF sessions (two OF, striped bars). Rats were injected in the dorsal hippocampus either with vehicle (veh, white bars) or anisomycin $80 \mu \mathrm{g} /$ side (gray bars) $85 \mathrm{~min}$ (5 min after the second OF session $[A, C]$ ) or $120 \mathrm{~min}$ (30 min before the second OF session $[B, D]$ ) before IA training with 0.5 -mA footshock. Rats were tested $24 \mathrm{~h}$ later to evaluate LTM. $(A, B)$ Bars represent medians of latencies with interquartile ranges (percentiles $25 ; 75$ ). (Tr) Training session; $(\mathrm{Tt})$ test session. $\left({ }^{*},{ }^{* *}\right)$ Significant differences between training and test latencies within the same group (Wilcoxon paired $t$-test, $\left[{ }^{*}\right] P<0.05$, $\left.\left[{ }^{* *}\right] P<0.01\right)$. $(C, D)$ Latency differences (LTM Tts - Tr) for the same groups in $A$ and $B$. Bars represent medians of latency differences with interquartile ranges (percentiles $25 ; 75)$. $\left({ }^{\#}, \# \#\right.$ \# Significant differences among latency differences (Multiple Comparisons Dunn's Test after ANOVA Kruskal-Wallis, $\left[{ }^{\#}\right] P<0.05$, $\left[{ }^{\# \# \#]} P<0.001\right.$ ). "Rats injected 85 min before $I A^{\prime \prime}$ : no OF groups: control and aniso, $n=10$; two OF groups: aniso, $n=11$. "Rats injected 120 min before IA": no OF groups: control, $n=9$ and aniso, $n=8$; two OF groups: aniso, $n=10$.

not show any significant effect (when animals were exposed once to the "novelty" $2 \mathrm{~h}, 30$, or 5 min before IA training, or either 2 or $6 \mathrm{~h}$ after training) (Netto et al. 1985; Izquierdo et al. 1999a; Blake et al. 2011). There is still another possibility when the novel experience promotes encoding of the IA task performed with a weak underthreshold stimulus, leading to LTM (Moncada and Viola 2007). In addition, exposure to a novel experience $1 \mathrm{~h}$ before a weak underthreshold training on either contextual fear conditioning (CFC) or spatial object recognition, promoted LTM formation (Ballarini et al. 2009), while extinction of CFC was also promoted by exposure to a novel OF (de Carvalho Myskiw et al. 2013).

Therefore, the exploration of an OF around a second task, particularly IA training, induces different effects on IA performance/retention, depending on the duration (e.g., 1 min vs. 3-5 min OF session, leading or not to habituation to the environment, respectively), the interval before and after IA training and the salience (footshock intensity) of the IA training.

In our experimental conditions, adult Wistar rats learned and expressed an LTM when trained in IA with a $0.5-\mathrm{mA}$ or higher stimulus, though not with $0.4 \mathrm{~mA}$ (Fig. 1A). Rats trained with $0.5 \mathrm{~mA}$-i.e., a mild overthreshold footshock-90 min after 3-min exploration of the $\mathrm{OF}$, did not show significant changes in performance for STM (Fig. 2A), nor for LTM either (Fig. 2B), neither for rats exploring once the OF (a "novel" experience; Fig. 4B), nor for those exploring twice the OF (a "familiar" experience; Figs. $2 \mathrm{~B}$ and $4 \mathrm{~A}$ ). Therefore, when the stimulus was overthreshold, the results are in agreement with the previous reports (Moncada and Viola 2007; Ballarini et al. 2009; de Carvalho Myskiw et al. 2013), within a similar interval. We considered that one session in the OF was a "novel" experience since it was the first and only one exposure to the OF. The second session was considered a "familiar" experience since rats showed habituation to the arena.

\section{Amnesia of IA by scopolamine}

Pharmacological experiments conducted in nonhuman animals (Deutsch 1971; see Klinkenberg and Blokland 2010), as well as in humans (Barak and Weiner 2010), have shown learning and memory deficits after MAChRs blockade (see Micheau and Marighetto 2010). Learning of an IA task depends on the activation of the cholinergic system (Baratti et al. 1979; Izquierdo et al. 1998; Jerusalinsky et al. 1998; Giovannini et al. 1999; Barros et al. 2002, for reviews, see Jerusalinsky et al. 1997; McGaugh 2000). Low doses of i.p. scopolamine given before training in a step-through version of the inhibitory avoidance (ST-IA) impaired retention tested $24 \mathrm{~h}$ later (Elrod and Buccafusco 1988; Ohno and Watanabe 1996). It has also been reported that, when given after training, a higher dose of scopolamine was necessary to impair memory (Roldan et al. 1997), suggesting a stronger effect on acquisition than on memory consolidation (Rush 1988). Thus, it was proposed that scopolamine would affect sensory perception and attention at lower doses $(<0.1 \mathrm{mg} / \mathrm{kg})$, and learning and memory at higher doses (see Klinkenberg and Blokland 2010). On the other hand, ST-IA training with a very high footshock, considered as an over-reinforcement, protected from the amnestic effect of a high dose $(4 \mathrm{mg} / \mathrm{kg})$ of systemic scopolamine (Duran-Arevalo et al. 1990; Quirarte et al. 1993, 1994).

The anterograde amnesia by scopolamine injected i.p. before training was reversed by administration of AJ23 (an A1-adenosine receptor antagonist) at the time of early consolidation, strongly suggesting that in this case, the process underlying this amnesia would have been operating mainly during the consolidation period rather than during acquisition (Harvey et al. 2012).

Although there are reports of the amnestic effect of 0.2 and $0.5 \mathrm{mg} / \mathrm{kg}$ of scopolamine on the step-through version of IA in rats (Pazzagli and Pepeu 1964; Feigley 1974; Vannucchi et al. 1997), in our experimental conditions $1 \mathrm{mg} / \mathrm{kg}$ of scopolamine was the lowest dose able to cause IA amnesia in the step-down version of this task, even when training was relatively weak. 


\section{Amnesia by i.p. scopolamine and the "OF effect"}

The systemic administration of scopolamine in mice 15 min before IA training impaired STM expression (Alpern and Marriott 1973; Botton et al. 2010).

We have evaluated the influence of a previous experience (OF) on the anterograde amnesia caused by the systemic administration of scopolamine before training with a mild overthreshold footshock $(0.5 \mathrm{~mA})$. As expected, this antagonist was amnestic for IA (Figs. 3 and 4), as had previously been widely reported (Decker and McGaugh 1989; Ohno and Watanabe 1996; Giovannini et al. 1999), affecting IA acquisition and/or early consolidation. These rats previously exposed to the OF and then treated with i.p. scopolamine expressed IA LTM (Fig. 4) though not STM (Fig. 3).

Besides the amnestic effect of scopolamine, there is controversial information on its effect on locomotor activity; an increase (with $0.056 \mathrm{mg} / \mathrm{kg}, 1$ and $2.5 \mathrm{mg} / \mathrm{kg}$ ) (Watanabe and Shimizu 1989; Day et al. 1991; Nomura et al. 1994; Sipos et al. 1999; Chintoh et al. 2003), a decrease (Pradhan and Roth 1968; Anisman et al. 1975; Besheer et al. 2001; Myhrer et al. 2004; Masuoka et al. 2006; Hodges et al. 2009), or even no effect on locomotor activity (Feigley 1974; Humby et al. 1999) have been reported after systemic administration of scopolamine in several assays using different memory and operant tasks. Thus, these putative effects of scopolamine appear to depend on various experimental factors such as animal strain, task, doses, training intensity, and time before training (see Klinkenberg and Blokland 2010). Therefore, this should be checked when evaluating scopolamine effect on cognitive function, particularly in tasks where locomotor activity is closely related to the main dependent variable (see Klinkenberg and Blokland 2010); i.e., shorter STM test latencies in i.p. scopolamine treated rats could be due to an increase in locomotor activity instead to an impairment of cognitive function. When locomotor activity was assessed in the OF following the systemic administration of scopolamine, after the same interval between i.p. injection and IA-STM test (Fig. 3), there were not significant differences between scopolamine treated and control animals, in either locomotor or exploratory activity (see Table 1). In addition, there was also an internal control for the challenge with scopolamine, since rats either exposed or not to the OF received same dose of scopolamine, through the same route at the same interval before IA training (Fig. 3). During the training session, scopolamine treated animals behaved like those injected with saline, as was corroborated both qualitatively by direct observation and quantitatively, since training latencies of both groups were not statistically different. Hence, the same dose of scopolamine that was amnestic for IA did not show any significant impact on locomotor activity (Table 1). Therefore, our results ruled out the possibility that the low score in test performance $40 \mathrm{~min}$ after IA training (STM), 60 min after i.p. scopolamine, could be due to changes in locomotor activity.

STM and LTM involve independent processes (see McGaugh 1966); e.g., while LTM could suffer extinction, STM persists (see McGaugh 1966; Izquierdo et al. 1999b).

Interestingly, caffeine administration prevented disruption produced by pretraining i.p. scopolamine in mice on IA STM, though not on LTM (Botton et al. 2010). One can speculate that caffeine could act by increasing the level of attention putatively impaired by pretraining scopolamine during acquisition; nevertheless, this was not "enough" to rescue LTM. Therefore, scopolamine should be acting not only by impairing attention but on another function involved in LTM formation, i.e., over acquisition and encoding of the trace. Taking into account the pharmacokinetics and pharmacodynamics, scopolamine is distributed to the brain 20-30 min after i.p. injection (Watanabe and Shimizu 1989) and its central effect persists beyond $120 \mathrm{~min}$ after applica- tion (Perlstein et al. 2002); scopolamine could have impaired retrieval (Barros et al. 2001; Azami et al. 2010), since it was still present in the brain at significant concentration during STM test. Although we cannot fully discard this possibility, it appears unlikely since pretreatment with caffeine preserved both kinds of memories when scopolamine was given post-training, being still present in the brain when STM was assessed (Botton et al. 2010); thus, it seems that scopolamine would not affect STM retrieval directly. We use a rather similar protocol for scopolamine administration; therefore, it is also unlikely that scopolamine might be directly affecting the retrieval during STM evaluation.

Although acquisition and consolidation depend on muscarinic transmission, the underlying mechanisms for both functions, as well as for STM and LTM formation, are different. Altogether, the reports above mentioned (see Izquierdo et al. 1999b; Botton et al. 2010; Klinkenberg and Blokland 2010) and our results strongly support that although scopolamine could act on attention, it also acts directly on memory processing. Muscarinic transmission appears to be required for acquisition, is certainly required for STM (is likely involved in attention), as well as during LTM consolidation of IA.

\section{IA amnesia by i.h. scopolamine and the OF effect}

Rats treated with intrahippocampal scopolamine immediately after mild IA training suffered retrograde amnesia as expected (Fig. 5), and this was attributed to a deficit in early consolidation (Izquierdo et al. 1992; see Izquierdo et al. 1999b). Then, we assessed the influence of a previous experience on that retrograde amnesia. The amnestic effect on LTM was prevented by exposure to one or two OF sessions, while STM assessed after two OF exposures was also rescued. Hence, the OF experience promoted retention and led to expression of a memory that otherwise seemed to be absent, since rats injected with scopolamine without previous OF exposure expressed neither IA-STM (Fig. 5A,B) nor IA-LTM (Fig. 5C,D).

Since rats showed habituation to the $\mathrm{OF}$ in the second session (Fig. 1B), it appears that IA memory was not exclusively influenced by the novel condition of the previous experience. Instead, it could be related to other aspects and features, such as the establishment of another LTM in the appropriate structure within the appropriate interval, and/or to changes in rat attention, particularly during acquisition. However, as there was no improvement in IA performance in naïve rats that previously explored the OF and were then trained in IA with a weak overthreshold stimulus, the last possibility appears unlikely.

As the interval between the second or the single exposure to the OF and the IA training is shortened, the overlapping of phenomena underlying the OF retrieval, the concomitant memory labilization and IA acquisition would turn interactions from positive to negative; thus, the sign of these interactions would depend on the interval between tasks and the resultant qualitative and quantitative degree of the overlapping.

\section{OF effect and endogenous acetylcholine}

Muscarinic agonists and antagonists are able to modulate hippocampal synaptic plasticity considered to underlie learning and memory at the cellular level. Either the release of endogenous ACh in vivo (Leung et al. 2003; Ovsepian et al. 2004) or the exogenous application of MAChR agonists in vitro, led to LTP facilitation (Boddeke et al. 1992; Shimoshige et al. 1997; Shinoe et al. 2005). It follows that the activation of hippocampal MAChRs by endogenous ACh should facilitate the induction of synaptic plasticity, thereby promoting the cognitive processing. Cortical and hippocampal ACh release (Day et al. 1991; Mizuno et al. 1991) is also positively correlated to behavioral arousal (Dudar et al. 
1979; Day et al. 1991; Mizuno et al. 1991) and attention processes (Dudar et al. 1979; Inglis and Fibiger 1995). Open-field exploration and habituation depend on the hippocampus and its cholinergic afferents (Izquierdo et al. 1992). It has been reported that rats exposed to a novel environment showed a marked increase in ACh extracellular levels at the hippocampus $(>250 \%$, lasting for $10 \mathrm{~min}$ and decreasing to $100 \%$ at $\sim 20-30 \mathrm{~min}$ ); this increase was positively correlated with exploratory behavior in a first OF exposure. When rats were reexposed, exploratory behavior and locomotor activity decreased indicating habituation, but the cholinergic activation appeared once again; moreover, there was a further increase $(>280 \%$ ) during and after the reexposure, persisting for $>40 \mathrm{~min}$. Hence, extracellular ACh levels are elevated in the hippocampus not only in response to novelty, but also during the second exposure to the same environment when behavioral habituation was evident (Thiel et al. 1998).

The prevention of scopolamine amnesia by the "OF effect" might be explained, at least in part, by the "previous increase" in ACh release, which would facilitate synaptic plasticity/metaplasticity in the hippocampus, leading to overcoming the amnesia due to hippocampal MAChR blockade. Another possible explanation is that OF exposure would recruit MAChR from regions/circuits other than those in the dorsal hippocampus, e.g., from cerebral cortex, that would contribute to the establishment of IA LTM. However, this does not explain why the previous OF also prevented IA-LTM amnesia caused by a more general blockade of MAChR by i.p. scopolamine.

For STM, previous OF exploration and habituation led to overcoming the amnesia by muscarinic blockade only when it was restricted to the dorsal hippocampus after training (Fig. 5A,B), but not with a widespread and earlier blockade (Fig. 3), suggesting that another region might be involved in this case. An increase in hippocampal and cortical ACh release promoted by the OF exploration could contribute to overcoming the effect of the subsequent hippocampal MAChRs blockade during IA memory consolidation. When there was a widespread muscarinic blockade during IA acquisition, an increase in hippocampal and cortical ACh release induced by the OF exploration (Thiel et al. 1998) could not be able to recruit synapses and circuits depending on muscarinic transmission from other regions at the time of acquisition, and consequently, there was not STM expression; surprisingly, OF exposure was able to prevent or reverse the amnesia for LTM in this case (even when tested in the same animals) (M Snitcofsky and NC Colettis, unpubl.). These results corroborate that different mechanisms underlie both types of memories (e.g., with the putative participation of other cholinergic as nicotinic receptors), indicate that some memory trace was formed even under scopolamine and suggest that an increase in ACh release could exert its effect before or during training (e.g., by leading to metaplasticity and/or lowering the threshold for synaptic plasticity) or later on, while scopolamine concentration diminishes in the brain (i.e., during consolidation).

As OF exposure was always previous to IA training, it is not clear whether the "OF anti-amnestic effect" was acting before, during or after acquisition. However, in addition to the interpretation in the previous paragraph, four facts lead us to speculate that this effect could be due, at least in part, to the rescue of the trace during early consolidation: (1) The amnestic effect of scopolamine administered i.p. before IA training was reversed by blocking adenosine-A1 receptors during consolidation, indicating that certain trace was actually formed even when MAChRs had been blocked during acquisition (Harvey et al. 2012); (2) the retrograde amnesia of both STM and LTM by scopolamine given intrahippocampus at early consolidation was also prevented by the OF; (3) the anterograde amnesia by pretraining scopolamine was not prevented for STM but it was for LTM, strongly suggesting that the OF effect was able to promote consolidation rather than to facilitate acquisition; and (4) there was no significant improvement of IA performance in naïve or saline injected animals previously exposed to either one or two OF sessions, despite the weak training that led to a poor rather improvable performance.

Interestingly, it was shown that preexposure to the IA box, though not to a different environment $24 \mathrm{~h}$ before IA training, avoided the amnesia instigated by AP5, a N-methyl-D-aspartate receptor (NMDAR) antagonist (Roesler et al. 1998). In addition, 2 OF exposures $24 \mathrm{~h}$ apart, also prevented the amnestic effect of the NMDAR channel blocker MK-801 infused into the hippocampus immediately after IA training (Cercato et al. 2014). Coincidentally, 5-min exploration of a new environment $1 \mathrm{~h}$ before a hippocampus-dependent "everyday appetitive" behavioral model, rescued memory from the amnesia instigated by hippocampal dopaminergic D1/D5 receptor blockade 15 min before the memory-encoding trial (Wang et al. 2010).

Altogether, the reports in the literature and the present results strongly suggest that there is an interval in which the presentation of either a novel or even repeated experience would help to overcome amnesia of a following task, caused by diverse amnestic agents administered either before or after training in this second task.

\section{Effect of hippocampal protein synthesis inhibition on IA performance}

The dominant view on the molecular basis of memory is that LTM formation depends on the de novo protein synthesis "initiated" by the corresponding experience (Davis and Squire 1984; Nader 2003; for reviews, see Frey and Morris 1998; Kandel 2001; Dudai 2002; Alberini 2008). It has been shown that drugs interfering with protein synthesis, i.e., by inhibiting translation around the time of IA training, led to amnesia (Freeman et al. 1995; Quevedo et al. 1999). Then, it was proposed that protein synthesis would be required for the establishment of an association, e.g., between a context and a shock (Frankland et al. 2004). In addition, it was shown that, in a different paradigm like extinction of CFC in rats, the extinction process was promoted by exposure to a novel OF environment $1-2 \mathrm{~h}$ before or $1 \mathrm{~h}$ after CFC test (extinction), and that this promotion was suppressed by inhibitors of protein synthesis (de Carvalho Myskiw et al. 2013).

Furthermore, a single learning experience would trigger two "protein synthesis waves": an earlier one around the training session and a later one, 3-6 h after training (Grecksch and Matthies 1980; Davis et al. 1981; Freeman et al. 1995; Quevedo et al. 1999; Cammarota et al. 2004). Coincidentally, it has been shown that LTM formation of IA in rats has two critical time windows when gene expression would be required in the hippocampus: one since $15 \mathrm{~min}$ before training to immediately after, and the other $3-6 \mathrm{~h}$ after training (Igaz et al. 2002).

Protein synthesis inhibitor anisomycin interfered with IA performance when administered either 15 min (Quevedo et al. 1999, 2004) or 20 min before training (Davis et al. 1981; Canal and Gold 2007), and $3 \mathrm{~h}$ after training, though not immediately or $6 \mathrm{~h}$ later. However, there were no reports on the effect of earlier administration of anisomycin on IA memory.

It has been reported that hippocampal early-LTP was "behaviorally reinforced" leading to late-LTP, by exposing rats to a novel environment though not to a familiar arena (Li et al. 2003; Straube et al. 2003b; Davis et al. 2004). That LTP reinforcement induced by novelty was blocked by a protein synthesis inhibitor applied just before exploration (Straube et al. 2003a).

The "synaptic tagging and capture hypothesis" (STC) was postulated to explain how the newly synthesized plasticity related proteins (PRPs) would interact with specific inputs. PRPs would be 
captured at specific synapses which were previously tagged by synaptic activity (Frey and Morris 1997, see Frey and Morris 1998): A synaptic tag would transiently label a synapse after activation, allowing the local recognition of newly synthesized PRPs, thus leading to an enduring change in transmission efficiency (see Martin and Kosik 2002).

To investigate whether the "OF effect" on the IA retrograde amnesia by i.h. scopolamine involves hippocampal protein synthesis, we first had to find out an interval to block protein synthesis without interfering with IA training, but close enough to inhibit protein synthesis putatively triggered by the OF.

Anisomycin injected into the hippocampus $85 \mathrm{~min}$ before IA training clearly impaired IA LTM leading to amnesia (Fig. 6A); it also produced a significant impairment of IA LTM when given $2 \mathrm{~h}$ before IA training, although it was not fully amnestic (Fig. 6B). Thus, anisomycin affected acquisition and/or early consolidation of IA when administered pretraining longer before than previously shown. Moncada and Viola (2007) have proposed that the promoting effect of a novel OF around the time of an underthreshold training in IA (that induced STM though not LTM), would require newly synthesized hippocampal proteins, and that there would be a "behavioral tagging" in which the OF exploration provides PRPs in the hippocampus, stabilizing a weak IA memory trace. However, since rats exposed to the OF and infused with anisomycin $1 \mathrm{~h}$ before IA training with an underthreshold stimulus did not express IA LTM, it was not feasible to discriminate if there was an effect on IA acquisition after protein synthesis inhibition in the hippocampus. Nevertheless, our results showed that when anisomycin was given even $2 \mathrm{~h}$ before training (Fig. 6B), the hippocampal protein synthesis supposedly required for LTM formation would still be affecting IA performance. Furthermore, when anisomycin was administered 85 min before IA training (Fig. 6A) there would likely be a more conspicuous blockade during training, impairing performance. Therefore, the resulting interval of when some hippocampal protein synthesis would be necessary to lead to IA memory encoding was wider than anticipated. Furthermore, our results also showed that $3 \mathrm{~min}$ in the OF, 90 min before IA training, led to overcoming the amnesia instigated by anisomycin given $85 \mathrm{~min}$ before training, immediately after the OF exploration (Fig. 6A). In addition, anisomycin given before the OF (although it did not lead to full amnesia of IA), it did not affect the rescue of IA memory either.

In conclusion, two OF exposures-with habituation-prevented anisomycin induced amnesia in IA (Fig. 6), suggesting that the hypothetic OF-instigated "synaptic tagging" (see Frey and Morris 1998) and PRPs synthesis could take place in a region not reached by the inhibitor.

Although OF modulation of IA LTM could involve hippocampal protein synthesis triggered during or following the second OF session, we were not able to detect it-or a putative window for it-since the protein synthesis blockade in that structure before or after the OF experience did not impede overcoming IA amnesia. Thus, with our experimental design it was not feasible to discriminate among protein synthesis required during IA acquisition/early consolidation and some synthesis putatively induced by the OF, required for its positive modulation on IA memory. Since the animals appeared fully amnesic when anisomycin was administered 85 min before IA training, though not $2 \mathrm{~h}$ before, these results strongly suggest that in the first case, protein synthesis was inhibited during an interval enough to impair IA acquisition/consolidation. If the OF provided some de novo synthesized ad hoc proteins shortly before, during or following OF exploration, this could take place in a region which does not (fully) overlap with the dorsal hippocampus where the synthesis was inhibited. However, other interpretations are feasible: e.g., there is the possibility that this OF effect would not require new protein synthesis within the hippocampus or wherever. Most evidence on the de novo protein synthesis as necessary substrate for memory comes from the use of inhibitors like anisomycin. However, there are reports on the overcoming of this amnesia through several procedures. Gold (2008) has shown that IA amnesia by anisomycin seems to be due to a profound alteration on the release of the three biogenic amines in the amygdala, where the inhibitor was administered. Hence, such effects must be taken into account, particularly as anisomycin "failed" to cause IA amnesia when rats were left to explore twice an OF before IA training.

The blockade of memory and synaptic plasticity by inhibition of protein synthesis does not necessarily imply that protein synthesis is essential for neural plasticity, but could suggest that the inhibition of protein synthesis is a poor condition for the appropriate functioning of neurons/circuits to make memories (see Gold 2008).

Taking into account that anisomycin given 85 min before IA training severely impaired retention of IA and when given 120 min before also produced a retention impairment by itself, it seems rather difficult to perform assays with both scopolamine and anisomycin, to discriminate a putative requirement for hippocampal protein synthesis in the "rescue of IA trace" by the OF.

To interpret our results it is necessary to make it clear that the previous experience could be novel or not; therefore, novelty would not be an absolute requirement for the previous task effect on preventing amnesia of a second task. It is rather difficult to fit our results into the frame of the STC hypothesis, since the PRPs synthesis putatively induced by the OF should take place in another related structure, which does not-fully-overlap with that involved in LTM acquisition/encoding of the following task; hence, it would be necessary to postulate that hippocampal and/or appropriate located tags should still be able to capture those PRPs. However, as the previous experience in the OF rescued that memory even in the presence of the inhibitor (see Gold 2008), our results fit well into another explanation proposing that the inhibition of protein synthesis leads to altered neural functions that would interfere with memory processing.

\section{Materials and Methods}

\section{Animals}

Adult male and female Wistar rats (200-250 g) bred in-house (outbreed stock from Veterinary School Animal Facility), were maintained in groups of four to six animals per cage, under a $12-\mathrm{h}$ light/dark inverted cycle with lights on from 8 p.m. to 8 a.m., at $25^{\circ} \mathrm{C}$ room temperature. Food and water were available ad libitum in their home cages. A periodic handling for $\sim 60$ sec per day, three times a week was performed. Three-month-old rats were submitted to surgery and/or behavioral tasks.

All experiments were performed in accordance with the Veterinary School Institutional Committee for Care and Use of Laboratory Animals (IACUC), University of Buenos Aires and with the International Brain Research Organization (IBRO), and are in compliance with the US National Research Council "Guide for the Care and Use of Laboratory Animals," eighth edition 2011 (NRC 2011), and the European Union Directive of $2010(2010 / 63 / \mathrm{EU})$.

\section{Drugs}

Anisomycin and scopolamine were purchased from Sigma. Eighty micrograms of anisomycin was infused in the dorsal hippocampus, in a volume of $0.8 \mu \mathrm{L}$ per side. Anisomycin was dissolved in $\mathrm{HCl}$, diluted in saline and adjusted to $\mathrm{pH} 7.4$ with $\mathrm{NaOH}$. Eight micrograms of scopolamine was infused into the dorsal hippocampus in a final volume of $1 \mu \mathrm{L}$ per side (intrahippocampal infusions). One milligram per kilogram was injected via i.p. in some animals, in a final volume of $0.5 \mathrm{~mL}$ (systemic i.p. injections). 
Scopolamine was dissolved in sterile saline solution for both intrahippocampal and i.p. injections.

\section{Surgery and drug administration}

Animals were anesthetised with ketamine/xylazine (i.p.; 75 and $10 \mathrm{mg} / \mathrm{kg}$, respectively), and were bilaterally implanted with 21-gauge guide cannulae aimed at a point $2.00 \mathrm{~mm}$ above the CA1 region of the dorsal hippocampus (coordinates A: $-4.3 \mathrm{~mm}$, L: $4.0 \mathrm{~mm}, \mathrm{~V}: 1.2 \mathrm{~mm}$ from Bregma [Paxinos and Watson 1996], for rats from our stock), using a stereotaxic apparatus for small animals. After surgery, animals received a single i.m. dose of the antibiotic enrofloxacin $(5 \mathrm{mg} / \mathrm{kg})$.

Intrahippocampal infusions: After recovery from surgery 4-6 d later, stainless steel pins were removed from their implanted cannulae. Then, either scopolamine, anisomycin or the vehicle was injected at a flux of $1 \mu \mathrm{L} / \mathrm{min}$, using a Hamilton $10-\mu \mathrm{L}$ syringe connected by a silicon tubing system to a 27 -gauge dental needle inserted through the guide cannula and protruding $2.0 \mathrm{~mm}$ beyond its tip, into the CA1 pyramidal layer of the dorsal hippocampus. Infusion was performed throughout $1 \mathrm{~min}$; the needles were left in place for 30 additional seconds to minimize backflow.

Anisomycin was infused in the dorsal hippocampus either 120 or 85 min before inhibitory avoidance training (see protocol schemes shown in Fig. 6). Scopolamine was infused into the dorsal hippocampus immediately after inhibitory avoidance training.

After the end of all behavioral procedures, examination of cannula placement was performed. Animals were euthanized by decapitation, and the brains were stored in buffered formalin solution for localization of the infusion sites, by magnifying lens exploration. Only data from animals with correct cannula implants (within $1 \mathrm{~mm}$ of the target coordinates; $95 \%$ of the rats) were included in statistical analysis.

I.p. injections: Scopolamine was infused via i.p. in some animals, 20 min before inhibitory avoidance training.

\section{Behavioral studies}

\section{Open field (OF)}

To evaluate the possible effect of a novel or a repeated exposure to the OF arena, each rat was left to freely explore the box $(60 \mathrm{~cm}$ long $\times 60 \mathrm{~cm}$ wide $\times 50 \mathrm{~cm}$ high) for 3 min (first session). To test possible effect on habituation, a second 3-min session was performed $24 \mathrm{~h}$ later. The number of rearings and crossings from one quadrant to another (25 quadrants drawn in the floor of $15.0 \times 13.3 \mathrm{~cm}$ each), were quantified in both sessions.

\section{Step-down inhibitory avoidance (IA)}

During the training session, rats were kindly placed onto an isolated plastic platform (30 cm wide, $10 \mathrm{~cm}$ long, and $1.5 \mathrm{~cm}$ high), away from the experimenter, facing to the wall on the left side of an acrylic box $(50 \times 25 \times 30 \mathrm{~cm})$; the grid floor was made of parallel bronze bars $(0.3 \mathrm{~cm}$ in diameter, set $0.5 \mathrm{~cm}$ apart $)$. Then, rats were allowed to freely explore the box. The latency for the animal to step-down from the platform onto the grid was recorded. When the rat placed its four paws onto the grid, a 5 -sec scrambled footshock (i.e., $0.4 ; 0.5$ or $0.6 \mathrm{~mA}$ ) was delivered to the grid floor. During the test session, $40 \mathrm{~min}$ or $24 \mathrm{~h}$ later, no shock was given, and stepping down latency was measured with a 120 sec cut-off time. We considered that rats formed a short-term memory (STM) or a long-term memory (LTM), reaching the learning criteria when test latencies were significantly higher than training latencies.

\section{Statistics}

For the IA task, nonparametric statistics was used because an upper time limit of $120 \mathrm{sec}$ was specified for the test session; as a consequence, test latencies did not follow a Gaussian distribution (Kolmogorov-Smirnov test of normality). Results are presented as medians with interquartile ranges (P25/P75).
Performance in the IA for each group was evaluated comparing the differences between test and training latencies with zero, for each animal, by paired Wilcoxon test; in this way, we were able to detect whether test latencies resulted significantly higher than training latencies, which is the learning criteria. When the comparison was done between two groups, nonparametric Mann-Whitney $U$ test was used to compare latency differences (test latency - training latency). When comparing three or more groups, nonparametric one-way ANOVA was used (KruskalWallis test).

In each experiment, we compared training latencies among groups to ensure they were similar: Their training latencies median was not statistically different $(P>0.05$, Mann-Whitney $U$ test for the comparison of two groups; Kruskal-Wallis, one-way ANOVA for the comparison of more than two groups).

Since most of the rats spent $<15 \mathrm{sec}$ onto the platform during the training session, data from animals with training latencies $>15 \mathrm{sec}$ were discarded from the statistical analysis. Furthermore, those animals spending longer (in general $>20 \mathrm{sec}$ ) seemed to explore either in an atypical way or to apparently freeze.

We compared the number of either rearings or crossings between the first and second OF session by paired Wilcoxon test. When the recorded parameters were significantly higher in first than in the second session we considered that the animals were habituated to the arena.

Statistically significant differences were considered when $P<0.05$, using GraphPad Prism 5.0 software (GraphPad Software).

\section{Acknowledgments}

We thank Carlos Blanco, André's Varani, and laboratory animal technician students for their contribution in animal breeding and assistance. This work was supported by UBACyT (M031) and PIP CONICET $(112,200,801,00300)$ grants.

\section{References}

Alberini CM. 2008. The role of protein synthesis during the labile phases of memory: revisiting the skepticism. Neurobiol Learn Mem 89: $234-246$.

Alpern HP, Marriott JG. 1973. Short-term memory: facilitation and disruption with cholinergic agents. Physiol Behav 11: 571-575.

Anisman H, Wahlsten D, Kokkinidis L. 1975. Effects of d-amphetamine and scopolamine on activity before and after shock in three mouse strains. Pharmacol Biochem Behav 3: 819-824.

Auerbach JM, Segal M. 1994. A novel cholinergic induction of long-term potentiation in rat hippocampus. J Neurophysiol 72: 2034-2040.

Azami NS, Piri M, Oryan S, Jahanshahi M, Babapour V, Zarrindast MR. 2010. Involvement of dorsal hippocampal $\alpha$-adrenergic receptors in the effect of scopolamine on memory retrieval in inhibitory avoidance task. Neurobiol Learn Mem 93: 455-462.

Ballarini F, Moncada D, Martinez MC, Alen N, Viola H. 2009. Behavioral tagging is a general mechanism of long-term memory formation. Proc Natl Acad Sci 106: 14599-14604.

Bammer G. 1982. Pharmacological investigations of neurotransmitter involvement in passive avoidance responding: a review and some new results. Neurosci Biobehav Rev 6: 247-296.

Barak S, Weiner I. 2010. Differential role of muscarinic transmission within the entorhinal cortex and basolateral amygdala in the processing of irrelevant stimuli. Neuropsychopharmacology 35: 1073-1082.

Baratti CM, Huygens P, Mino J, Merlo A, Gardella J. 1979. Memory facilitation with posttrial injection of oxotremorine and physostigmine in mice. Psychopharmacology (Berl) 64: 85-88.

Barros DM, Mello e Souza T, De David T, Choi H, Aguzzoli A, Madche C, Ardenghi P, Medina JH, Izquierdo I. 2001. Simultaneous modulation of retrieval by dopaminergic $\mathrm{D}(1), \beta$-noradrenergic, serotonergic-1A and cholinergic muscarinic receptors in cortical structures of the rat. Behav Brain Res 124: $1-7$.

Barros DM, Pereira P, Medina JH, Izquierdo I. 2002. Modulation of working memory and of long- but not short-term memory by cholinergic mechanisms in the basolateral amygdala. Behav Pharmacol 13: $163-167$.

Besheer J, Short KR, Bevins RA. 2001. Dopaminergic and cholinergic antagonism in a novel-object detection task with rats. Behav Brain Res 126: $211-217$. 
Blake MG, Boccia MM, Krawczyk MC, Baratti CM. 2011. Scopolamine prevents retrograde memory interference between two different learning tasks. Physiol Behav 102: 332-337.

Boddeke EW, Enz A, Shapiro G. 1992. SDZ ENS 163, a selective muscarinic M1 receptor agonist, facilitates the induction of long-term potentiation in rat hippocampal slices. Eur J Pharmacol 222: 21-25.

Botton PH, Costa MS, Ardais AP, Mioranzza S, Souza DO, da Rocha JB, Porciuncula LO. 2010. Caffeine prevents disruption of memory consolidation in the inhibitory avoidance and novel object recognition tasks by scopolamine in adult mice. Behav Brain Res 214: $254-259$.

Cammarota M, Bevilaqua LR, Medina JH, Izquierdo I. 2004. Retrieval does not induce reconsolidation of inhibitory avoidance memory. Learn Mem 11: 572-578.

Canal CE, Gold PE. 2007. Different temporal profiles of amnesia after intra-hippocampus and intra-amygdala infusions of anisomycin. Behav Neurosci 121: 732-741.

Cercato M, Colettis NC, Snitcofsky M, Aguirre AI, Kornisiuk EE, Baez MV, Jerusalinsky DA. 2014. Hippocampal NMDA receptor and the previous experience effect on memory. J of Physiol doi: 10.1016/ j.jphysparis.2014.08.001.

Chintoh A, Fulton J, Koziel N, Aziz M, Sud M, Yeomans JS. 2003. Role of cholinergic receptors in locomotion induced by scopolamine and oxotremorine-M. Pharmacol Biochem Behav 76: 53-61.

Davis HP, Squire LR. 1984. Protein synthesis and memory: a review. Psychol Bull 96: 518-559.

Davis HP, Rosenzweig MR, Kinkade PT, Bennett EL. 1981. Effects of anisomycin on retention of the passive-avoidance habit as a function of age. Exp Aging Res 7: 33-44.

Davis CD, Jones FL, Derrick BE. 2004. Novel environments enhance the induction and maintenance of long-term potentiation in the dentate gyrus. J Neurosci 24: 6497-6506.

Day J, Damsma G, Fibiger HC. 1991. Cholinergic activity in the rat hippocampus, cortex and striatum correlates with locomotor activity: an in vivo microdialysis study. Pharmacol Biochem Behav 38: 723-729.

de Carvalho Myskiw J, Benetti F, Izquierdo I. 2013. Behavioral tagging of extinction learning. Proc Natl Acad Sci 110: 1071-1076.

Decker MW, McGaugh JL. 1989. Effects of concurrent manipulations of cholinergic and noradrenergic function on learning and retention in mice. Brain Res 477: 29-37.

Deutsch JA. 1971. The cholinergic synapse and the site of memory. Science 174: $788-794$

Deutsch JA, Rocklin KW. 1967. Amnesia induced by scopolamine and its temporal variations. Nature 216: 89-90.

Diehl F, Furstenau de Oliveira L, Sanchez G, Camboim C, de Oliveira Alvares L, Lanziotti VB, Cervenansky C, Kornisiuk E, Jerusalinky D, Quillfeldt JA. 2007. Facilitatory effect of the intra-hippocampal pre-test administration of MT3 in the inhibitory avoidance task. Behav Brain Res 177: $227-231$.

Dudai Y. 2002. Molecular bases of long-term memories: a question of persistence. Curr Opin Neurobiol 12: 211-216.

Dudar JD, Whishaw IQ, Szerb JC. 1979. Release of acetylcholine from the hippocampus of freely moving rats during sensory stimulation and running. Neuropharmacology 18: 673-678.

Duran-Arevalo M, Cruz-Morales SE, Prado-Alcala RA. 1990. Is acetylcholine involved in memory consolidation of over-reinforced learning? Brain Res Bull 24: 725-727.

Eglen RM. 2006. Muscarinic receptor subtypes in neuronal and nonneuronal cholinergic function. Auton Autacoid Pharmacol 26: 219-233.

Eichenbaum H, Dudchenko P, Wood E, Shapiro M, Tanila H. 1999. The hippocampus, memory, and place cells: is it spatial memory or a memory space? Neuron 23: 209-226.

Elrod K, Buccafusco JJ. 1988. An evaluation of the mechanism of scopolamine-induced impairment in two passive avoidance protocols. Pharmacol Biochem Behav 29: 15-21.

Everitt BJ, Robbins TW. 1997. Central cholinergic systems and cognition. Annu Rev Psychol 48: 649-684.

Feigley DA. 1974. Effects of scopolamine on activity and passive avoidance learning in rats of different ages. J Comp Physiol Psychol 87: 26-36.

Frankland PW, Bontempi B. 2005. The organization of recent and remote memories. Nat Rev Neurosci 6: 119-130.

Frankland PW, Josselyn SA, Anagnostaras SG, Kogan JH, Takahashi E, Silva AJ. 2004. Consolidation of CS and US representations in associative fear conditioning. Hippocampus 14: 557-569.

Freeman FM, Rose SP, Scholey AB. 1995. Two time windows of anisomycin-induced amnesia for passive avoidance training in the day-old chick. Neurobiol Learn Mem 63: 291-295.

Frey U, Morris RG. 1997. Synaptic tagging and long-term potentiation. Nature 385: $533-536$

Frey U, Morris RG. 1998. Synaptic tagging: implications for late maintenance of hippocampal long-term potentiation. Trends Neurosci 21: $181-188$.
Giovannini MG, Bartolini L, Bacciottini L, Greco L, Blandina P. 1999. Effects of histamine $\mathrm{H} 3$ receptor agonists and antagonists on cognitive performance and scopolamine-induced amnesia. Behav Brain Res 104: 147-155.

Gold PE. 2008. Protein synthesis inhibition and memory: formation vs amnesia. Neurobiol Learn Mem 89: 201-211.

Grecksch G, Matthies H. 1980. Two sensitive periods for the amnesic effect of anisomycin. Pharmacol Biochem Behav 12: 663-665.

Harvey AL, Young LC, Kornisiuk E, Snitcofsky M, Colettis N, Blanco C, Jerusalinsky D, Jamieson AG, Hartley RC, Stone TW. 2012. A novel dihydro-pyrazolo $(3,4 \mathrm{~d})(1,2,4)$ triazolo $(1,5 \mathrm{a})$ pyrimidin-4-one (AJ23) is an antagonist at adenosine $\mathrm{A}(1)$ receptors and enhances consolidation of step-down avoidance. Behav Brain Res 234: 184-191.

Hodges DB Jr, Lindner MD, Hogan JB, Jones KM, Markus EJ. 2009. Scopolamine induced deficits in a battery of rat cognitive tests: comparisons of sensitivity and specificity. Behav Pharmacol 20: 237-251.

Huang ZB, Wang H, Rao XR, Zhong GF, Hu WH, Sheng GQ. 2010. Different effects of scopolamine on the retrieval of spatial memory and fear memory. Behav Brain Res 221: 604-609.

Humby T, Laird FM, Davies W, Wilkinson LS. 1999. Visuospatial attentional functioning in mice: interactions between cholinergic manipulations and genotype. Eur J Neurosci 11: 2813-2823.

Igaz LM, Vianna MR, Medina JH, Izquierdo I. 2002. Two time periods of hippocampal mRNA synthesis are required for memory consolidation of fear-motivated learning. J Neurosci 22: 6781-6789.

Inglis FM, Fibiger HC. 1995. Increases in hippocampal and frontal cortical acetylcholine release associated with presentation of sensory stimuli. Neuroscience 66: 81-86.

Izquierdo I. 1989. Different forms of post-training memory processing. Behav Neural Biol 51: 171-202.

Izquierdo I, Medina JH. 1997. Memory formation: the sequence of biochemical events in the hippocampus and its connection to activity in other brain structures. Neurobiol Learn Mem 68: $285-316$.

Izquierdo I, Pereira ME. 1989. Post-training memory facilitation blocks extinction but not retroactive interference. Behav Neural Biol 51: $108-113$.

Izquierdo I, da Cunha C, Rosat R, Jerusalinsky D, Ferreira MB, Medina JH. 1992. Neurotransmitter receptors involved in post-training memory processing by the amygdala, medial septum, and hippocampus of the rat. Behav Neural Biol 58: 16-26.

Izquierdo I, Medina JH, Izquierdo LA, Barros DM, de Souza MM, Mello e Souza T. 1998. Short- and long-term memory are differentially regulated by monoaminergic systems in the rat brain. Neurobiol Learn Mem 69: 219-224.

Izquierdo I, Schroder N, Netto CA, Medina JH. 1999a. Novelty causes time-dependent retrograde amnesia for one-trial avoidance in rats through NMDA receptor- and CaMKII-dependent mechanisms in the hippocampus. Eur J Neurosci 11: 3323-3328.

Izquierdo I, Medina JH, Vianna MR, Izquierdo LA, Barros DM. 1999b. Separate mechanisms for short- and long-term memory. Behav Brain Res 103: $1-11$.

Jerusalinsky D, Kornisiuk E, Izquierdo I. 1997. Cholinergic neurotransmission and synaptic plasticity concerning memory processing. Neurochem Res 22: 507-515.

Jerusalinsky D, Kornisiuk E, Alfaro P, Quillfeldt J, Alonso M, Verde ER, Cervenansky C, Harvey A. 1998. Muscarinic toxin selective for m4 receptors impairs memory in the rat. Neuroreport 9: 1407-1411.

Kandel ER. 2001. The molecular biology of memory storage: a dialogue between genes and synapses. Science 294: 1030-1038.

Klinkenberg I, Blokland A. 2010. The validity of scopolamine as a pharmacological model for cognitive impairment: a review of animal behavioral studies. Neurosci Biobehav Rev 34: 1307-1350.

Leung LS, Shen B, Rajakumar N, Ma J. 2003. Cholinergic activity enhances hippocampal long-term potentiation in CA1 during walking in rats. I Neurosci 23: 9297-9304.

Li S, Cullen WK, Anwyl R, Rowan MJ. 2003. Dopamine-dependent facilitation of LTP induction in hippocampal CA1 by exposure to spatial novelty. Nat Neurosci 6: 526-531.

Martin KC, Kosik KS. 2002. Synaptic tagging-who's it? Nat Rev Neurosci 3: $813-820$.

Masuoka T, Fujii Y, Kamei C. 2006. Effect of scopolamine on the hippocampal $\theta$ rhythm during an eight-arm radial maze task in rats. Eur J Pharmacol 539: 76-80.

McGaugh JL. 1966. Time-dependent processes in memory storage. Science 153: 1351-1358.

McGaugh JL. 2000. Memory-a century of consolidation. Science 287: $248-251$.

McGaugh JL, Izquierdo I. 2000. The contribution of pharmacology to research on the mechanisms of memory formation. Trends Pharmacol Sci 21: 208-210. 
Micheau J, Marighetto A. 2010. Acetylcholine and memory: a long, complex and chaotic but still living relationship. Behav Brain Res 221: $424-429$.

Miranda MI, Bermudez-Rattoni F. 1999. Reversible inactivation of the nucleus basalis magnocellularis induces disruption of cortical acetylcholine release and acquisition, but not retrieval, of aversive memories. Proc Natl Acad Sci 96: 6478-6482.

Mizuno T, Endo Y, Arita J, Kimura F. 1991. Acetylcholine release in the rat hippocampus as measured by the microdialysis method correlates with motor activity and exhibits a diurnal variation. Neuroscience 44: 607-612.

Moncada D, Viola H. 2007. Induction of long-term memory by exposure to novelty requires protein synthesis: evidence for a behavioral tagging. J Neurosci 27: 7476-7481.

Morris RG, Garrud P, Rawlins JN, O'Keefe J. 1982. Place navigation impaired in rats with hippocampal lesions. Nature 297: 681-683.

Myhrer T, Enger S, Aas P. 2004. Cognitive side effects in rats caused by pharmacological agents used to prevent soman-induced lethality. Eur J Pharmacol 483: 271-279.

Nadel L, Moscovitch M. 1997. Memory consolidation, retrograde amnesia and the hippocampal complex. Curr Opin Neurobiol 7: 217-227.

Nader K. 2003. Memory traces unbound. Trends Neurosci 26: 65-72.

Netto CA, Dias RD, Izquierdo I. 1985. Interaction between consecutive learnings: inhibitory avoidance and habituation. Behav Neural Biol 44: $515-520$

Nomura Y, Nishiyama N, Saito H, Matsuki N. 1994. Role of cholinergic neurotransmission in the amygdala on performances of passive avoidance learning in mice. Biol Pharm Bull 17: 490-494.

Ohno M, Watanabe S. 1996. Interactive processing between glutamatergic and cholinergic systems involved in inhibitory avoidance learning of rats. Eur J Pharmacol 312: 145-147.

Ovsepian SV, Anwyl R, Rowan MJ. 2004. Endogenous acetylcholine lowers the threshold for long-term potentiation induction in the CA1 area through muscarinic receptor activation: in vivo study. Eur J Neurosc 20: $1267-1275$.

Paxinos G, Watson C. 1996. The rat brain in stereotaxic coordinate, Compact 3rd ed. Academic Press, New York.

Pazzagli A, Pepeu G. 1964. [Correlations between the modifications of behavior induced by scopolamine and cerebral acetylcholine contents in the rat]. Rass Studi Psichiatr 53: 261-266.

Pepeu G, Giovannini MG. 2004. Changes in acetylcholine extracellular levels during cognitive processes. Learn Mem 11: 21-27.

Perlstein I, Stepensky D, Krzyzanski W, Hoffman A. 2002. A signal transduction pharmacodynamic model of the kinetics of the parasympathomimetic activity of low-dose scopolamine and atropine in rats. J Pharm Sci 91: 2500-2510.

Pitsikas N, Rigamonti AE, Cella SG, Locatelli V, Sala M, Muller EE. 2001. Effects of molsidomine on scopolamine-induced amnesia and hypermotility in the rat. Eur J Pharmacol 426: 193-200.

Pradhan SN, Roth T. 1968. Comparative behavioral effects of several anticholinergic agents in rats. Psychopharmacologia 12: 358-366.

Quevedo J, Vianna MR, Roesler R, de-Paris F, Izquierdo I, Rose SP. 1999. Two time windows of anisomycin-induced amnesia for inhibitory avoidance training in rats: protection from amnesia by pretraining but not pre-exposure to the task apparatus. Learn Mem 6: 600-607.

Quevedo J, Vianna MR, Martins MR, Barichello T, Medina JH, Roesler R, Izquierdo I. 2004. Protein synthesis, PKA, and MAP kinase are differentially involved in short- and long-term memory in rats. Behav Brain Res 154: 339-343.

Quirarte GL, Cruz-Morales SE, Diaz del Guante MA, Garcia M, Prado-Alcala RA. 1993. Protective effect of under-reinforcement of passive avoidance against scopolamine-induced amnesia. Brain Res Bull 32: $521-524$.
Quirarte GL, Cruz-Morales SE, Cepeda A, Garcia-Montanez M, Roldan-Roldan G, Prado-Alcala RA. 1994. Effects of central muscarinic blockade on passive avoidance: anterograde amnesia, state dependency, or both? Behav Neural Biol 62: 15-20.

Roesler R, Vianna M, Sant'Anna MK, Kuyven CR, Kruel AV, Quevedo J, Ferreira MB. 1998. Intrahippocampal infusion of the NMDA receptor antagonist AP5 impairs retention of an inhibitory avoidance task: protection from impairment by pretraining or preexposure to the task apparatus. Neurobiol Learn Mem 69: 87-91.

Roldan G, Bolanos-Badillo E, Gonzalez-Sanchez H, Quirarte GL, Prado-Alcala RA. 1997. Selective M1 muscarinic receptor antagonists disrupt memory consolidation of inhibitory avoidance in rats. Neurosci Lett 230: 93-96.

Rush DK. 1988. Scopolamine amnesia of passive avoidance: a deficit of information acquisition. Behav Neural Biol 50: 255-274.

Sanchez G, Alvares Lde O, Oberholzer MV, Genro B, Quillfeldt J, da Costa JC, Cervenansky C, Jerusalinsky D. 2009. M4 muscarinic receptors are involved in modulation of neurotransmission at synapses of Schaffer collaterals on CA1 hippocampal neurons in rats. J Neurosci Res 87: 691-700.

Sarter M, Bruno JP. 2000. Cortical cholinergic inputs mediating arousal, attentional processing and dreaming: differential afferent regulation of the basal forebrain by telencephalic and brainstem afferents. Neuroscience 95: 933-952.

Sarter M, Bruno JP, Givens B. 2003. Attentional functions of cortical cholinergic inputs: what does it mean for learning and memory? Neurobiol Learn Mem 80: 245-256.

Shimoshige Y, Maeda T, Kaneko S, Akaike A, Satoh M. 1997. Involvement of M2 receptor in an enhancement of long-term potentiation by carbachol in Schaffer collateral-CA1 synapses of hippocampal slices. Neurosci Res 27: 175-180.

Shinoe T, Matsui M, Taketo MM, Manabe T. 2005. Modulation of synaptic plasticity by physiological activation of M1 muscarinic acetylcholine receptors in the mouse hippocampus. J Neurosci 25: $11194-11200$.

Sipos ML, Burchnell V, Galbicka G. 1999. Dose-response curves and time-course effects of selected anticholinergics on locomotor activity in rats. Psychopharmacology (Berl) 147: 250-256.

Straube T, Korz V, Frey JU. 2003a. Bidirectional modulation of long-term potentiation by novelty-exploration in rat dentate gyrus. Neurosci Lett 344: $5-8$.

Straube T, Korz V, Balschun D, Frey JU. 2003b. Requirement of $\beta$-adrenergic receptor activation and protein synthesis for LTP-reinforcement by novelty in rat dentate gyrus. J Physiol 552: 953-960.

Thiel CM, Huston JP, Schwarting RK. 1998. Hippocampal acetylcholine and habituation learning. Neuroscience 85: 1253-1262.

Ukai M, Kobayashi T, Kameyama T. 1994. Characterization of the effects of scopolamine on the habituation of exploratory activity: differential effects of oxotremorine and physostigmine. Gen Pharmacol 25: 433-438.

Vannucchi MG, Scali C, Kopf SR, Pepeu G, Casamenti F. 1997. Selective muscarinic antagonists differentially affect in vivo acetylcholine release and memory performances of young and aged rats. Neuroscience 79: $837-846$.

Wang SH, Redondo RL, Morris RG. 2010. Relevance of synaptic tagging and capture to the persistence of long-term potentiation and everyday spatial memory. Proc Natl Acad Sci 107: 19537-19542.

Watanabe H, Shimizu H. 1989. Effect of anticholinergic drugs on striatal acetylcholine release and motor activity in freely moving rats studied by brain microdialysis. Jpn J Pharmacol 51: 75-82.

Received June 20, 2014; accepted in revised form July 28, 2014. 


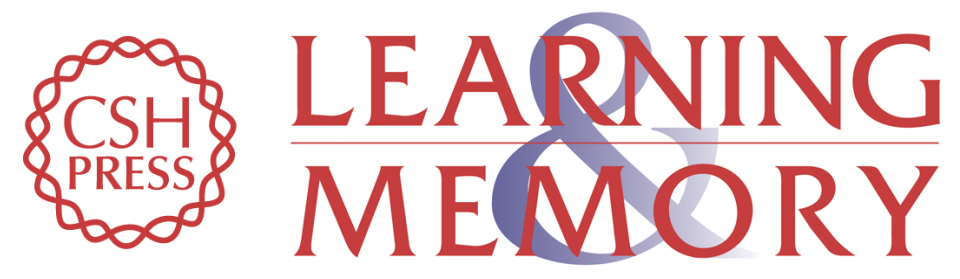

\title{
Amnesia of inhibitory avoidance by scopolamine is overcome by previous open-field exposure
}

\author{
Natalia C. Colettis, Marina Snitcofsky, Edgar E. Kornisiuk, et al.
}

Learn. Mem. 2014, 21:

Access the most recent version at doi:10.1101//m.036210.114

\section{Supplemental http://learnmem.cshlp.org/content/suppl/2014/09/18/21.11.634.DC1 Material}

References

Creative

Commons

License

Email Alerting
This article cites 105 articles, 16 of which can be accessed free at: http://learnmem.cshlp.org/content/21/11/634.full.html\#ref-list-1

This article is distributed exclusively by Cold Spring Harbor Laboratory Press for the first 12 months after the full-issue publication date (see

http://learnmem.cshlp.org/site/misc/terms.xhtml). After 12 months, it is available under a Creative Commons License (Attribution-NonCommercial 4.0 International), as described at http://creativecommons.org/licenses/by-nc/4.0/.

Service top right corner of the article or click here. 